\title{
Sistem Informasi Inventory Barang Pada PT. Assami Ananda Berbasis Java Neatbeans
}

\author{
Harri Mukti $^{1}$; Ida Fitriani ${ }^{2}$; Fajar Erlangga ${ }^{3}$ \\ ${ }^{1,2,3}$ Program Studi Informatika, Universitas Indraprasta PGRI \\ ${ }^{1}$ harri.mukti17@gmail.com \\ 2idafitriani2604@gmail.com \\ 3 erlangga.dawn@gmail.com
}

\begin{abstract}
In a company engaged in sales, inventory is very important so that sales run well and customer needs are always met. When doing research at PT. Assami Ananda, the authors find out data entry still using manual method, so it is not effective and efficient. Therefore, the authors make a design of a Java-based inventory information system design using Netbeans software which aims to facilitate the admin in making inventory data and has database using MySQL so that the security of data storage more awake. The research method used is grounded research where the results of collecting data needed by the author are obtained accurately to make a system design, while in developing more specific systems the writer uses the waterfall method with the obtained result are designing an inventory system that can facilitate the admin in processing goods inventory data and making reports.
\end{abstract}

Keywords: Information Systems, Inventory of Goods, Java, Netbeans, MySQL

\begin{abstract}
ABSTRAK
Dalam perusahaan yang bergerak dibidang penjualan, inventory barang sangat penting agar aktivitas penjualan berjalan dengan baik serta kebutuhan pelanggan selalu terpenuhi. Pada saat melakukan penelitian di PT. Assami Ananda penulis mengetahui sistem pendataan inventory barang yang berjalan masih menggunakan cara manual sehingga kurang efektif dan efisien. Maka dari itu, penulis membuat suatu perancangan sistem informasi inventory barang berbais Java dengan menggunakan software Netbeans yang bertujuan untuk memudahkan admin dalam melakukan pembuatan data inventory barang dan memiliki basis data menggunakan MySQL sehingga keamanan penyimanan data lebih terjaga. Metode penelitian yang digunakan yaitu grounded research dimana hasil dari mengumpulkan data yang dibutuhkan oleh penulis didapat secara akurat untuk membuat suatu perancangan sistem, sementara dalam pengembangan sistem yang lebih spesifik penulis menggunakan metode waterfall dengan hasil yang didapat yaitu perancangan sistem inventory yang dapat mempermudah admin dalam mengolah data inventory barang serta pembuatan laporan.
\end{abstract}

Kata kunci: Sistem Informasi, Inventory Barang, Java, Netbeans, MySQL 


\section{PENDHULUAN}

Inventory barang pada suatu perusahaan sangat penting, karena dengan adanya data inventory barang, pengelolaan stok barang untuk dijual kepada konsumen menjadi lebih jelas dan terstruktur. Oleh karena itu, perusahaan harus bisa mengelola data inventory barang dengan akurat, efektif dan efisien. Teknologi Informasi merupakan suatu alat bantu yang dapat digunakan oleh manusia dalam mengolah data inventory barang ini.

PT. Assami Ananda merupakan salah satu perusahaan yang bergerak dalam bidang ritel supermarket bahan bangunan. Saat ini sistem infomasi inventory barang yang berjalan masih menggunakan pembukuan sederhana, sehingga kurang efektif dan efisien dalam waktu pengerjaan serta saat data semakin bertambah banyak akan terjadi kesulitan dalam mencari data yang diinginkan. Penulis melakukan penelitian ini dengan harapan dapat membantu menyelesaikan setiap kendala yang dihadapi oleh admin PT. Assami Ananda dalam melakukan pendataan inventory barang serta pembuatan laporan yang dibutuhkan.

\section{METODE/PERANCANGAN PENELITIAN}

\subsection{Kajian Pustaka}

Sistem merupakan seperangkat elemen yang saling bergantung yang bersama-sama mencapai tujuan tertentu[1].Informasi adalah data yang telah dikelola dan di proses untuk memberikan arti dan memperbaiki proses pengambilan keputusan[2]. Sistem informasi adalah suatu sistem didalam suatu organisasi yang mempertemukan kebutuhan pengolahan transaksi harian yang mendukung fungsi operasi organisasi yang bersifat manajerial dengan kegiatan strategi dari suatu organisasi untuk dapat menyediakan laporan-laporan yang diperlukan oleh pihak luar tertentu[3]. Sistem informasi dapat didefinisikan juga sebagai sekumpulan tahap kegiatan organisasi yang pada saat dijalankan akan memberikan informasi untuk pengambil keputusan dan untuk mengendalikan organisasi[4]. Sementara sistem inventori keluar masuk barang adalah kegiatan yang terdiri dari data masuknya barang, data retur serta data persediaan barang yang melaporkan seluruh transaksi keluar masuk barang dari perhari sampai perbulan[5].

Java adalah bahasa pemrograman yang dapat dijalankan diberbagai perangkat komputer, termasuk pada telepon seluler, dikembangkan oleh Sun Microsystem dan dirilis pada 1995[6]. bahasa pemrograman java merupakan salah satu dari sekian banyak bahasa pemrograman yang dapat dijalankan diberbagai sistem operasi termasuk telepon genggam[7].

Data adalah fakta-fakta mentah kemudian dikelola sehingga menghasilkan informasi yang penting bagi sebuah perusahaaan atau organisasi[8]. Prinsip utama basis data adalah pengaturan data dengan tujuan utama fleksibilitas dan kecepatan dalam pengambilan data kembali[9]. DBMS (Database Management System) adalah suatu system perangkat lunak yang memungkinkan pengguna untuk mendefinisikan, membuat, memelihara dan mengontrol akses database[10]. Suatu sistem aplikasi disebut DBMS jika memenuhi persyaratan minimal diantaranya menyediakan fasilitas untuk mengelola akses data, mampu menangani integritas data, mampu menangani akses data, mampu menangani backup data[11]. Database MySQL adalah salah satu jenis database server yang sangat terkenal dan banyak digunakan untuk membangun aplikasi web yang menggunakan database sebagai sumber dan pengolahan datanya[12]. 


\subsection{Metode Penelitian}

Metode penelitian adalah suatu cara ilmiah untuk mendapatkan data dengan tujuan kegunaan tertentu[13]. Untuk mencapai tujuan yang diperlukan dibutuhkan metode yang relevan untuk mencapai tujuan yang diinginkan[14].

Metode yang digunakan dalam penelitian ini yaitu grounded research dimana studi-studi perbandingan bertujuan untuk menentukan seberapa jauh suatu gejala berlaku di umum. Penelitian juga bertujuan untuk menspesifikasikan konsep, maksudnya dalam mempelajari suatu kasus atau gejala maka perlu untuk membandingkan gejala atau kasus tersebut dengan kasus atau gejala serupa. Langkah-langkah dalam grounded research yaitu menentukan masalah yang ingin diselidiki, menentukan data-data yang dibutuhkan, Analisis dan penjelasan, pembuatan laporan.

\subsection{Metode Pengembangan Sistem}

Dalam pengembangan sistem informasi inventory barang pada PT Assami Ananda, metode yang digunakan yaitu metode waterfall, Model waterfall adalah paradigm tertua untuk rekayasa perangkat lunak[15]. yang meliputi proses-proses sebagai berikut:

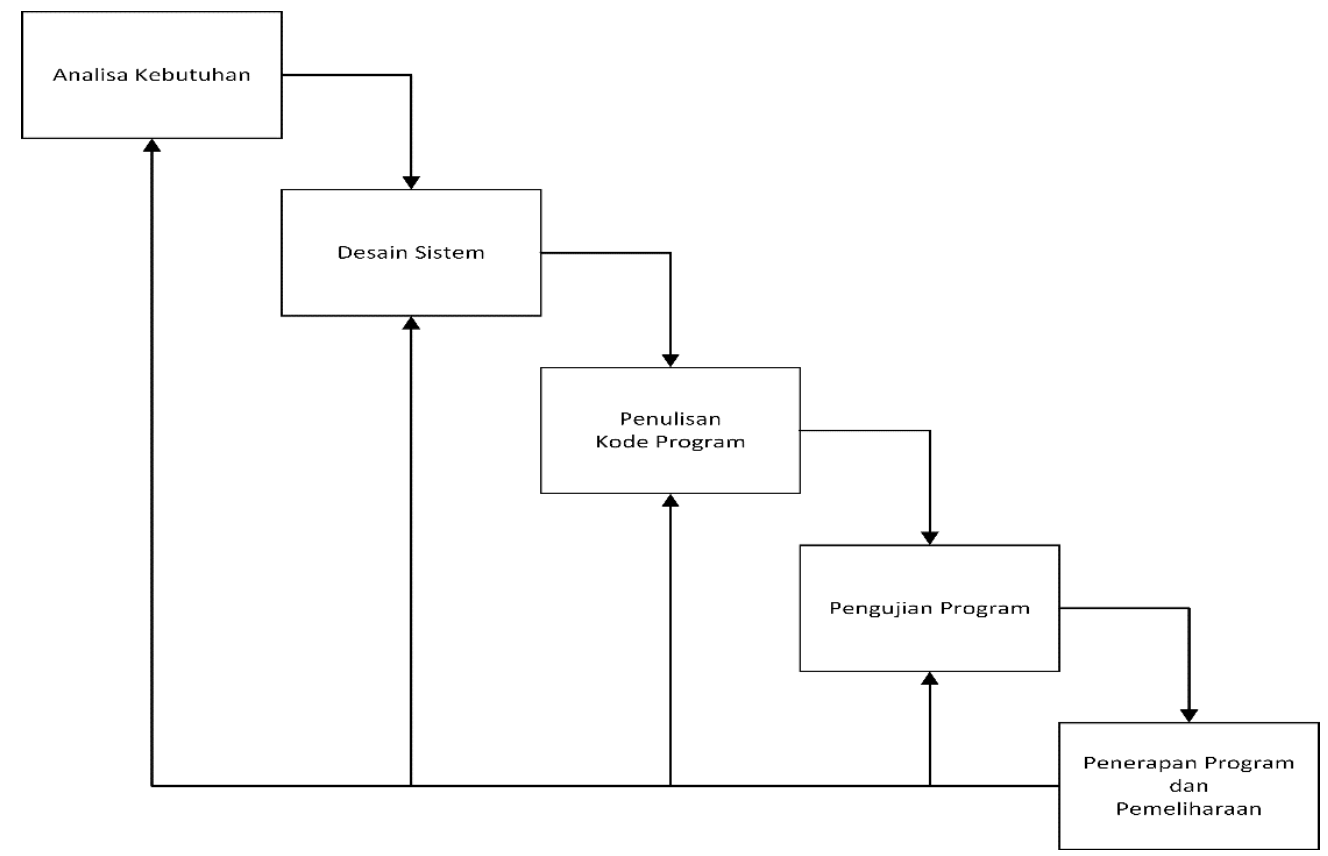

Gambar 1. Metode Waterfall

Berdasarkan gambar metode waterfall di atas dapat dijelaskan sebagai berikut:

1. Analisis Kebutuhan

Dalam langkah ini merupakan analisa terhadap kebutuhan sistem. Pengumpulan data pada tahap ini bisa membuat sebuah penelitian, wawancara atau literatur study.

2. Desain Sistem

Proses desain akan menterjemahkan syarat kebutuhan ke sebuah perancangan perangkat lunak yang dapat diperkirakan sebelum dibuat coding.

3. Penulisan Kode Program

Coding merupakan penerjemahan desain dalam bahasa yang bisa dikenali oleh komputer.

4. Pengujian Program 
Untuk memastikan apakah semua sistem dapat bekerja dengan baik, maka mencari apakah masih ada kesalahan pada siste.

5. Penerapan Program dan Pemeliharaan

Setelah melakukan analisa, desain dan pengkodean maka sistem yang sudah jadi akan digunakan oleh user.

\section{HASIL DAN PEMBAHASAN}

Perancangan sistem ini adalah langkah untuk meningkatkan efektifitas kinerja karyawan dalam bidang data inventory barang. Aplikasi ini diharapkan dapat membantu PT Assami Ananda sehingga dapat melakukan kegiatan-kegiatan dalam inventory barang dengan cepat, tepat, akurat serta efektif dan efisien. Berikut proses bisnis pada sistem yang diusulkan diantaranya :

1. Proses Barang Masuk

Pertama staff admin mendapat laporan ketersediaan barang yang habis ataupun stok terbatas dari bagian gudang, kemudian membuat pesanan pembelian yang diserahkan kepada pemasok. Setelah pemasok mengirimkan barang maka staff admin membuat Data barang masuk.

2. Proses Barang Keluar

Saat ada pemesanan pembelian dari pihak pelanggan maka staff admin akan melakukan pengecekan produk kepada staff gudang dan apabila tersedia stok maka akan dibuat bukti pembelian dan membuat data barang keluar.

3. Proses Pembuatan Laporan

Ketika data barang masuk dan data barang keluar sudah sesuai dengan fisik barang yang ada maka staff admin akan membuat laporan barang masuk dan laporan barang keluar untuk diserahkan kepada manager.

Berikut ini merupakan penggambaran sistem yang pada PT. Assami Ananda secara keseluruhan dalam bentuk diagram konteks, tabel normalisasi, dan ERD.

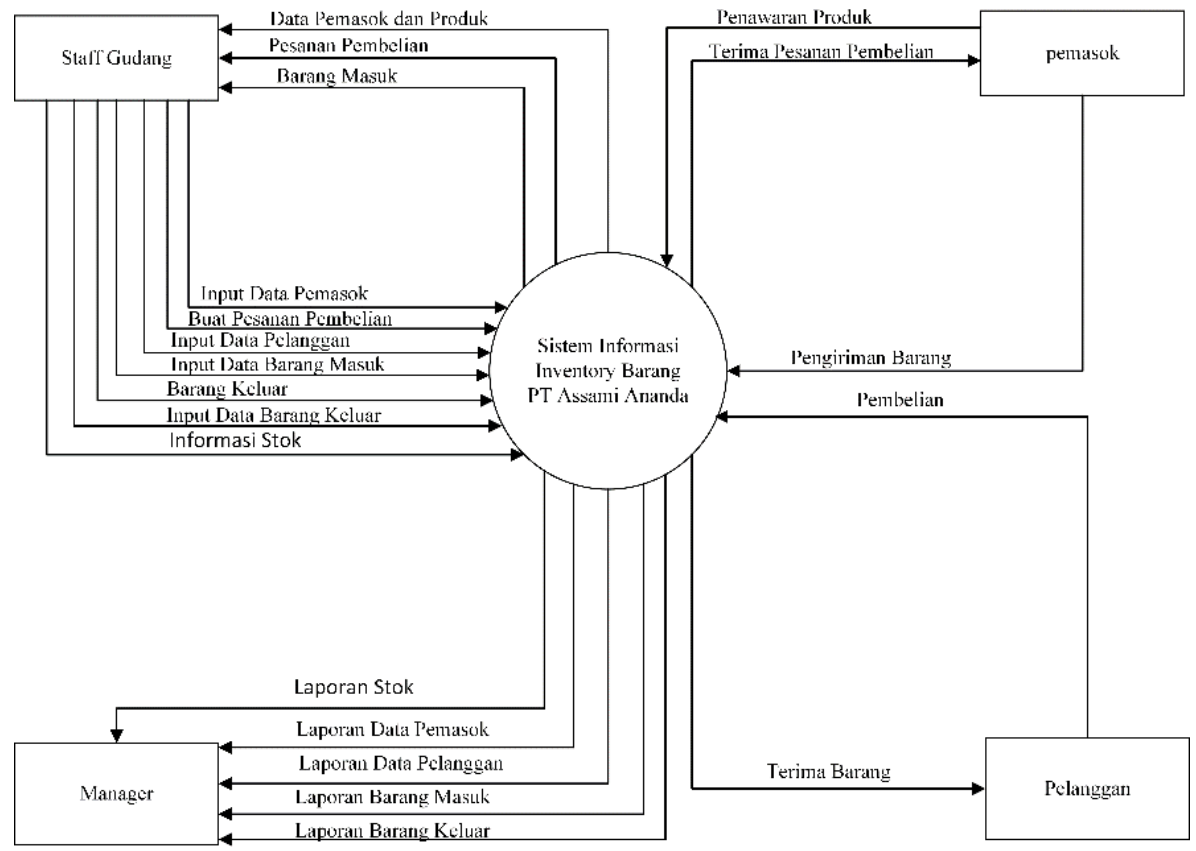

Gambar 2. Diagram Konteks Sistem yang Diusulkan 


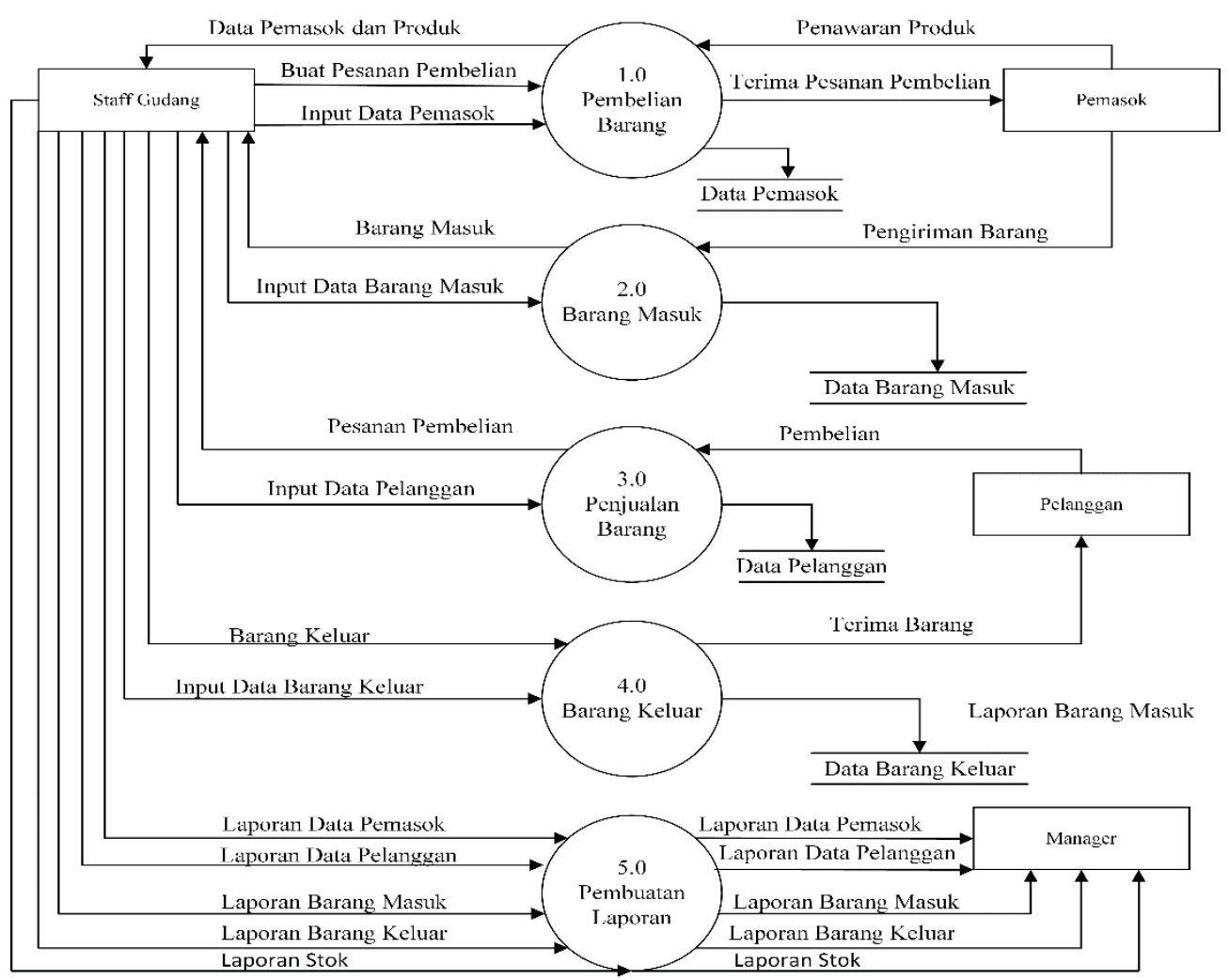

Gambar 3. Diagram Nol Sistem yang Diusulkan

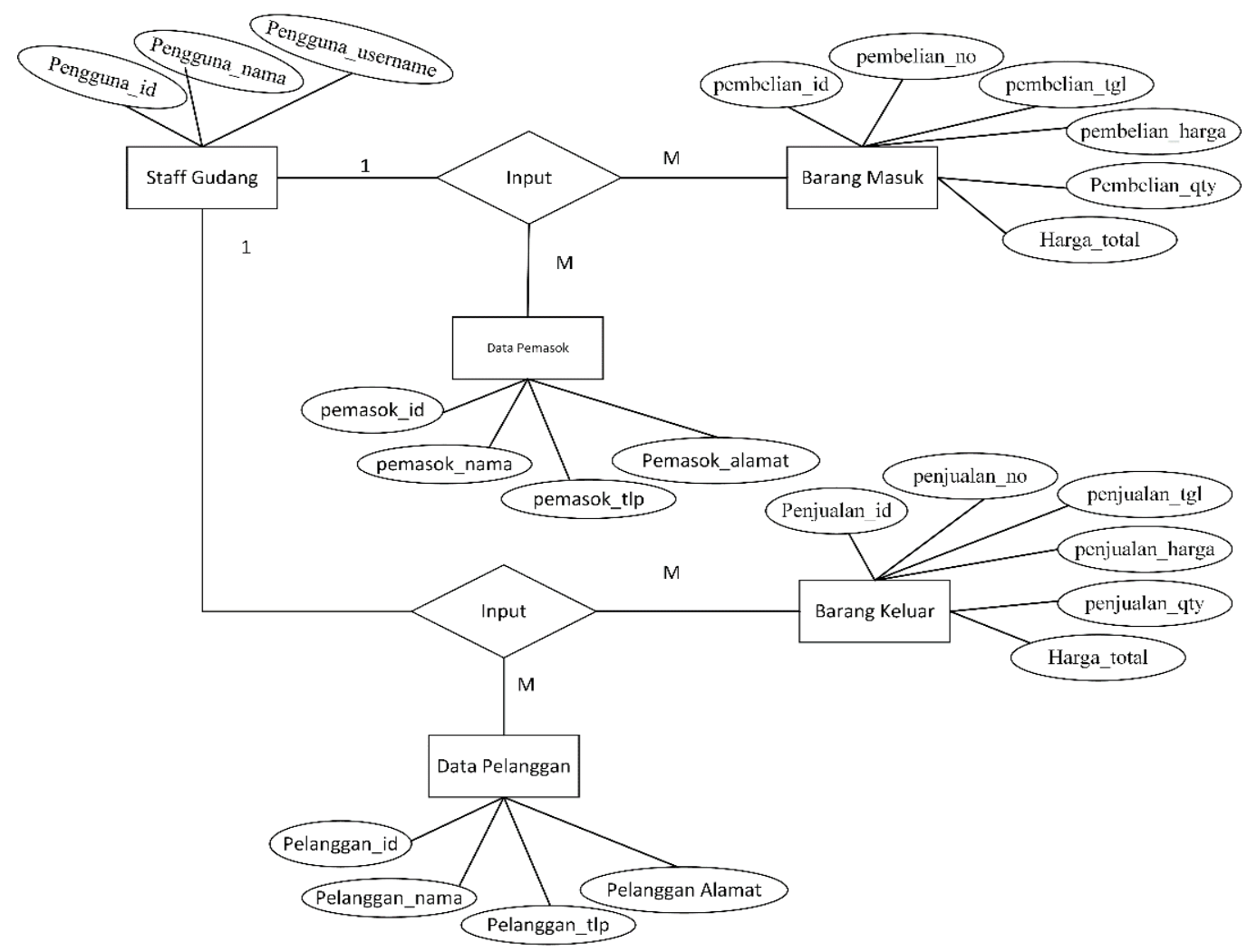

Gambar 4. ERD Sistem yang Diusulkan 
Berikut ini merupakan tampilan layar dari sistem informasi inventory barang pada PT Assami Ananda:

1. Tampilan Login sistem

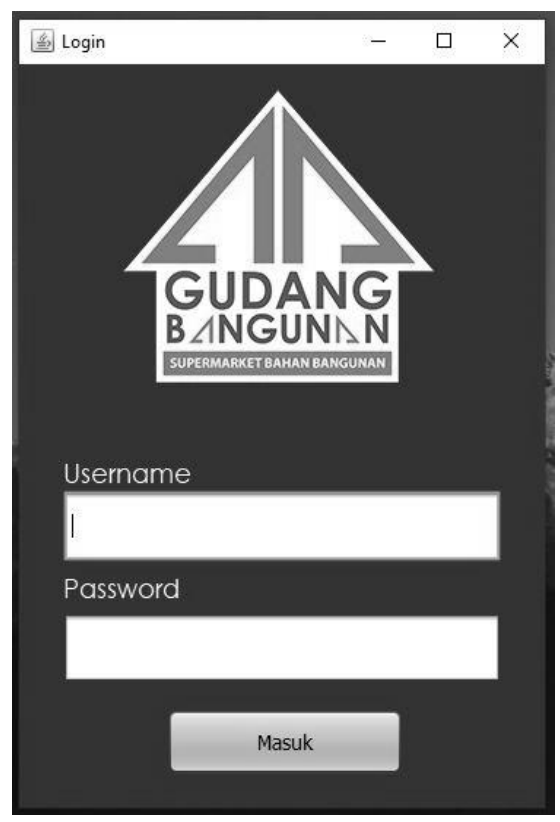

Gambar 5. Tampilan Login Sistem

Pada menu login ini digunakan untuk membuka sistem. Untuk username dan password diisikan sesuai dengan data yang ada pada database.

2. Tampilan Menu Utama

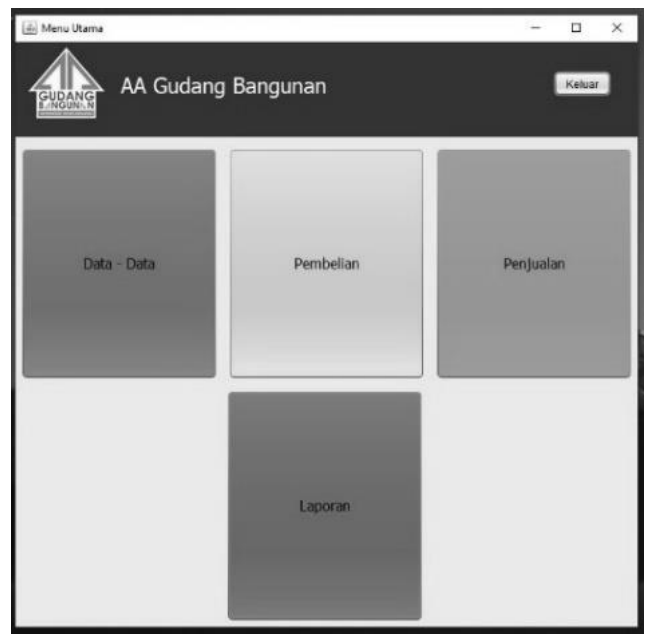

Gambar 6. Tampilan Menu Utama

Pada menu utama terdapat 4 pilihan menu, yaitu Data-data, Pembelian, Penjualan, Laporan dan ditambah dengan satu tombol Keluar. 
3. Tampilan Data-Data

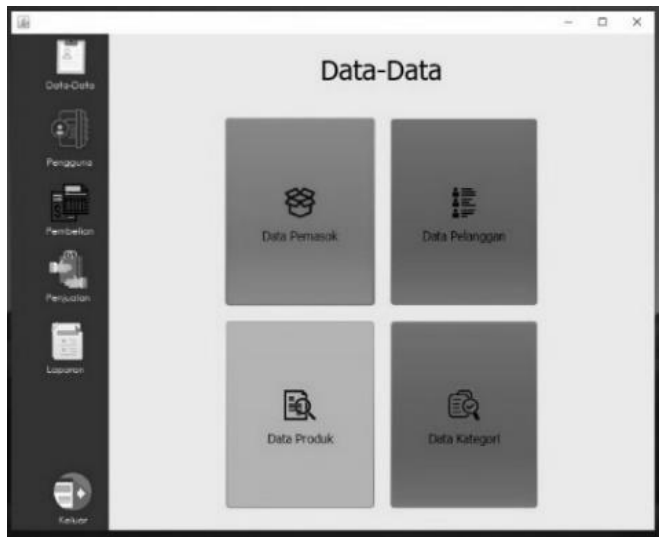

Gambar 7. Tampilan Data-Data

Pada menu data-data terdapat 4 pilihan menu yaitu data pemasok, data pelanggan, data produk dan data kategori.

4. Tampilan Data Pembelian

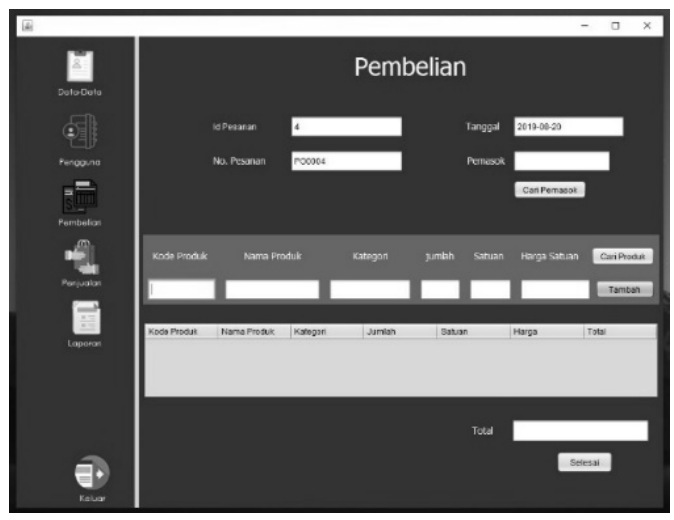

Gambar 8. Tampilan Data Pembelian

Tampilan ini berada di dalam menu utama dan menu samping Pada tampilan ini terdapat empat tombol untuk melakukan proses, tombol cari pemasok, tombol cari produk, tombol tambah, tombol selesai.

5. Tampilan Data Penjualan

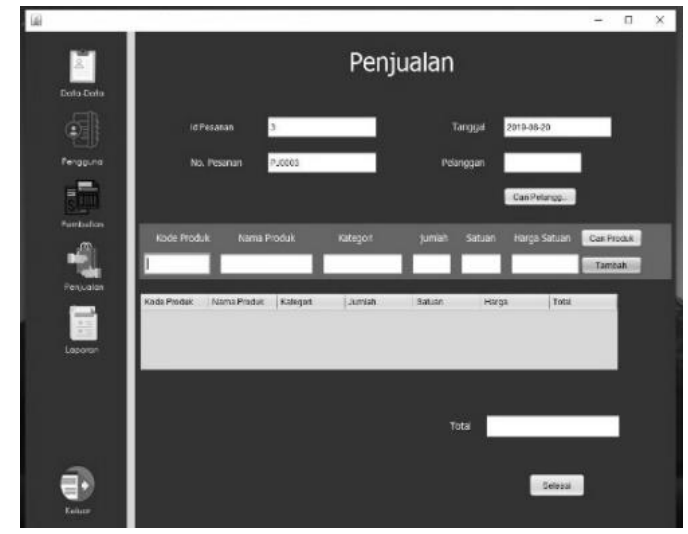

Gambar 9. Tampilan Data Penjualan 
Tampilan ini berada di dalam menu utama dan menu samping. Pada tampilan ini terdapat empat tombol untuk melakukan proses, tombol cari pelanggan, tombol cari produk, tombol tambah, tombol selesai.

6. Tampilan Menu Laporan

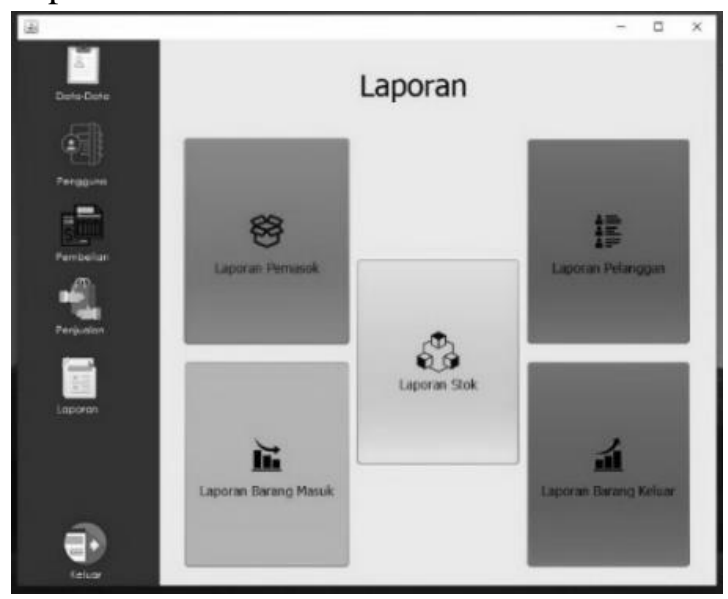

Gambar 10. Tampilan Menu Laporan

Pada menu laporan terdapat 4 pilihan menu yaitu laporan pemasok, laporan pelanggan, laporan barang masuk, laporan barang keluar dan laporan stok.

7. Laporan Data Pemasok

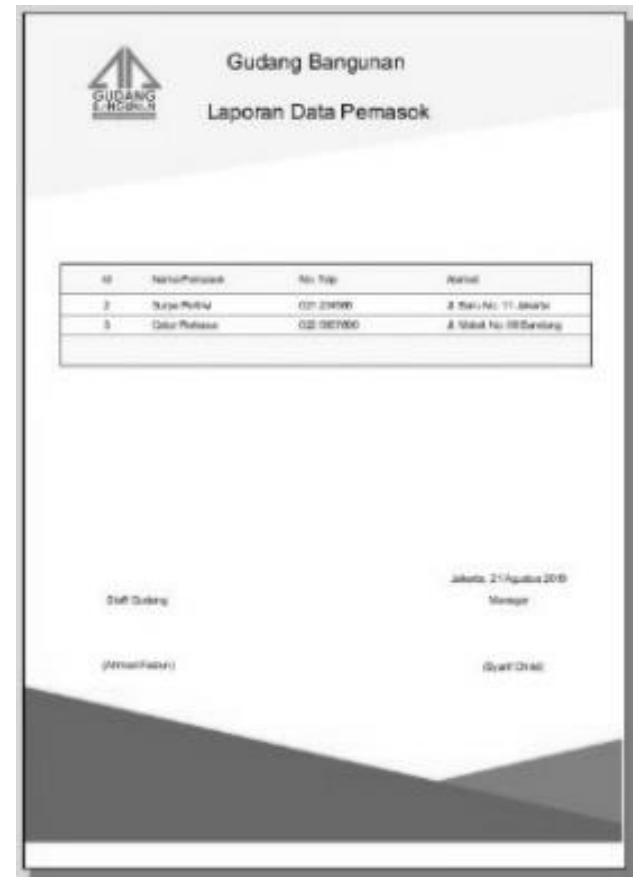

Gambar 11. Tampilan Laporan Data Pemasok

Tampilan ini merupakan laporan data pemasok yang telah diinput dan di simpan pada menu data pemasok. 
8. Tampilan Laporan Data Pelanggan

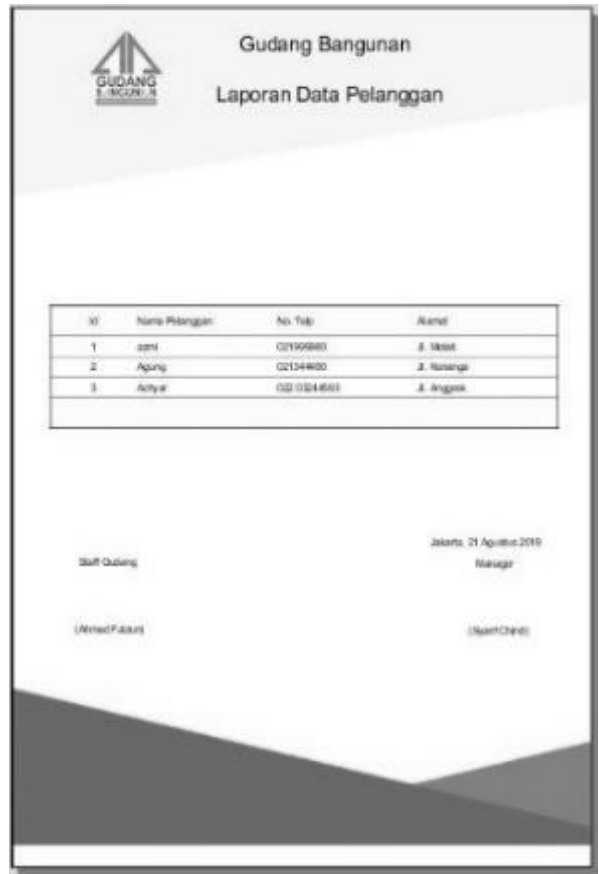

Gambar 12. Tampilan Laporan Data Pelanggan

Tampilan ini merupakan laporan data pelanggan yang telah diinput dan di simpan pada menu data pelanggan.

9. Tampilan Laporan Barang Masuk

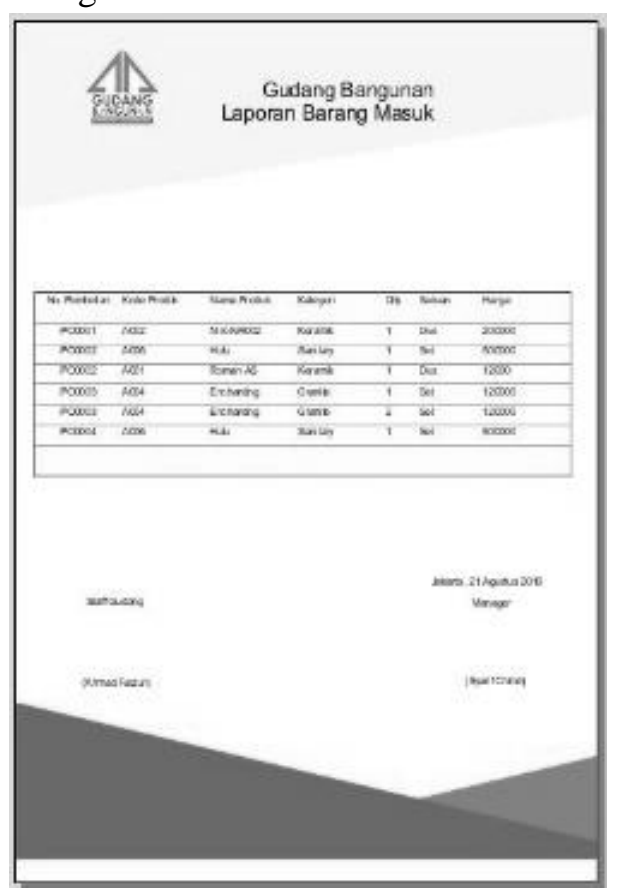

Gambar 13. Tampilan Laporan Barang Masuk

Tampilan ini merupakan laporan data barang masuk yang telah diinput dan disimpan pada menu pembelian. 
10. Tampilan Laporan Barang Keluar

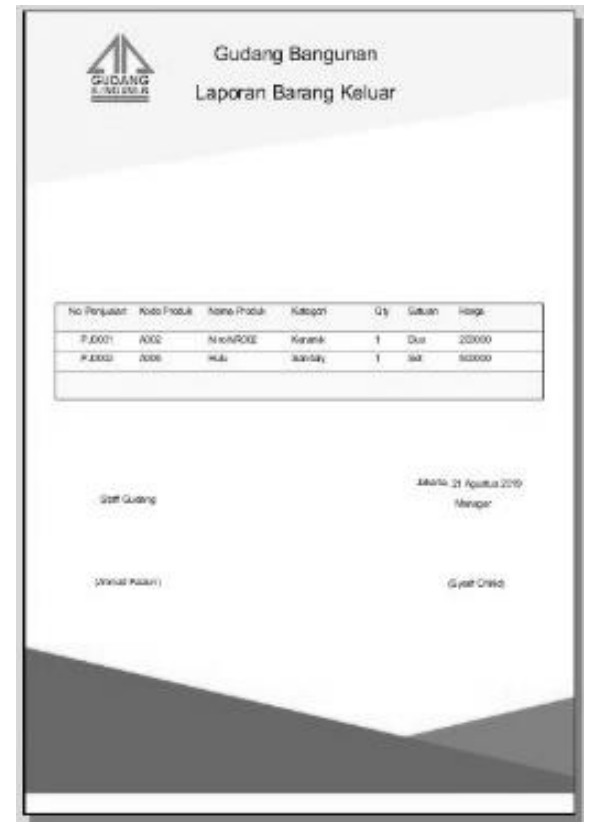

Gambar 14. Tampilan Laporan Barang Keluar

Tampilan ini merupakan laporan data barang keluar yang telah diinput dan di simpan pada menu penjualan.

11. Tampilan Laporan Stok

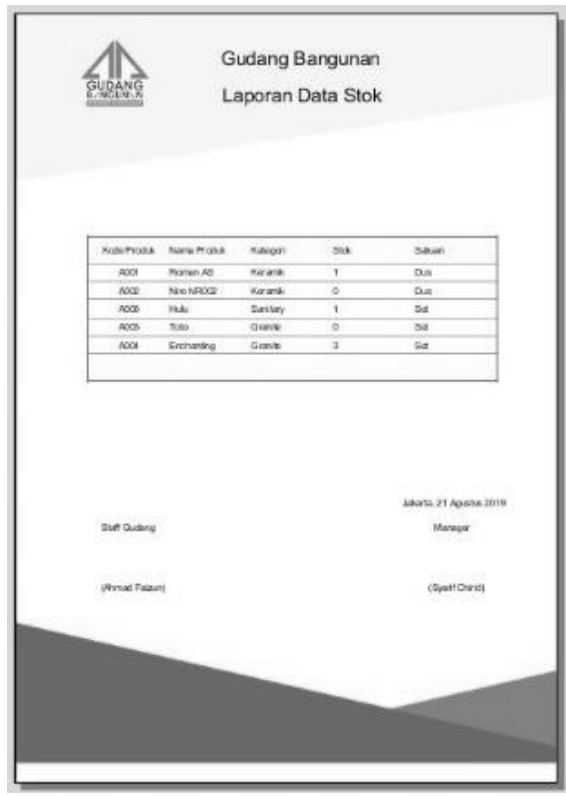

Gambar 15. Tampilan Laporan Stok

Tampilan ini merupakan laporan data stok yang ditmbah pada data pembelian dan dikurangi dari data penjualan. 


\section{SIMPULAN DAN SARAN}

\subsection{Simpulan}

Dengan dibuatnya sistem inventory barang pada PT Assami Ananda diharapkan kinerja pegawai menajadi lebih produktif, efektif serta efisien. Sistem informasi inventory barang ini menyediakan form input yang dapat menyimpannya di database untuk memudahkan dalam pembuatan data inventory barang dan mencegah terjadinya kehilangan data. Penggunaan progam tidak didapat dilakukan oleh semua orang karena program ini memiliki fitur login yang menjadikan hanya orang-orang yang diberikan akses saja yang dapat menjalankan program ini.

\subsection{Saran}

Penulis menyarankan agar program ini bisa dikembangkan dengan lebih baik lagi, dengan penambahan fitur-fitur baru yang dapat lebih memudahkan bagi penggunanya.

\section{UCAPAN TERIMAKASIH}

Penulis berharap program ini bisa dikembangkan dengan lebih baik lagi, mengucapkan terima kasih kepada PT Assami Ananda dan dosen pembimbing, yang telah memberikan bantuan serta bimbingannya sehingga penelitian ini dapat terlaksanan dengan baik.

\section{DAFTAR PUSTAKA}

[1] U. J. Gelinas, R. B. Dull, and P. Wheeler, Accounting Information Systems, 9th ed. Stamford: Cengage Learning, 2011.

[2] M. B. Romney and P. J. Steinbart, Accounting Information Systems, 13th ed. London: PEARSON, 2015.

[3] T. Sutabri, Analisis Sistem Informasi, 1st ed. Yogyakarta: Andi Offset, 2012.

[4] Bin Ladjamudin, "Analisis dan Desain Sistem Informasi," Anal. dan Desain Sist. Inf., 2013, doi: 10.1017/CBO9781107415324.004.

[5] R. A. Wibowo, "Sistem Informasi Persediaan Keluar Masuk Barang Pada Inside Distro Jakarta," Spead, 2009.

[6] H. Kurniawan and Dkk., Aplikasi Inventory Menggunakan Java Netbeans, Xampp, dan iReport. Jakarta: Elex Media Komputindo, 2013.

[7] Nofriadi, Java Fundamental Dengan Netbeans 8.0.2. Yogyakarta: Deepublis, 2015.

[8] Indrajani, Database Systems All in One Theory, Practice, and Case Study. Jakarta: PT Elex Media Komputindo, 2015.

[9] Yakub, Pengantar Sistem Informasi, 1st ed. Yogyakarta: Graha Ilmu, 2012.

[10] T. Connolly and C. Begg, Database Systems: A Practical Approach to Design, Imp.lementation, and Management 6th edition, 2nd ed. Boston: Pearson Education (US), 2015.

[11] A. . Rosa and M. Shalahuddin, "Rekayasa Perangkat Lunak Terstruktur," in Informatika, Bandung: Informatika, 2013.

[12] M. R. Arief, Pemrograman Web Dinamis Menggunakan PHP dan MySQL. Andi Offset, 2011.

[13] H. Darmadi, Metode Penelitian Pendidikan dan Sosial, 1st ed. Bandung: Alfabeta, 2013.

[14] P. D. Sugiyono, metode penelitian kuantitatif, kualitatif,dan R\&D. Alfabeta, 2016.

[15] R. Taufiq, Sistem Informasi Manajemen Konsep Dasar, Analisis dan Metode Pengembangan. Yogyakarta: Graha Ilmu, 2013 